\title{
Circuit
}

Musiques contemporaines

\section{Exigence, fidélité}

\section{Michel Gonneville}

Volume 28, numéro 2, 2018

URI : https://id.erudit.org/iderudit/1051298ar

DOI : https://doi.org/10.7202/1051298ar

Aller au sommaire du numéro

\section{Éditeur(s)}

Circuit, musiques contemporaines

\section{ISSN}

1183-1693 (imprimé)

1488-9692 (numérique)

Découvrir la revue

Citer ce document

Gonneville, M. (2018). Exigence, fidélité. Circuit, 28(2), 108-109.

https://doi.org/10.7202/1051298ar

Ce document est protégé par la loi sur le droit d'auteur. L'utilisation des services d'Érudit (y compris la reproduction) est assujettie à sa politique d'utilisation que vous pouvez consulter en ligne.

https://apropos.erudit.org/fr/usagers/politique-dutilisation/
Cet article est diffusé et préservé par Érudit.

Érudit est un consortium interuniversitaire sans but lucratif composé de l’Université de Montréal, l'Université Laval et l'Université du Québec à Montréal. Il a pour mission la promotion et la valorisation de la recherche. https://www.erudit.org/fr/ 


\section{Exigence, fidélité}

Michel Gonneville

En essayant de suppléer à une mémoire ingrate pour remonter aux origines de ma relation avec Véronique Lacroix et l'Ensemble contemporain de Montréal, je retrouve le programme de ce qui a probablement été le premier concert de l'ECM auquel j’aie assisté: associant l'interprétation de «classiques» du répertoire (le Siegfried Idyll de Wagner et des extraits de la Suite lyrique de Berg) à des créations d'un jeune compositeur québécois (Marc Hyland) et de deux artistes multidisciplinaires (Yergeau/Yergeau), un événement où danse et installation visuelle entouraient la musique, ce concert de 1991 intitulé Un matin sur Terre affichait déjà les caractéristiques de ce que l'on appelle aujourd'hui les «concerts thématiques» de l'ECM+, et qui sont l'une des raisons qui ont justifié l'apposition de ce + au nom initial de l'ensemble.

Je ne répèterai pas ce que chacun peut lire sur le site de l'Ecm+. «Plus qu'un ensemble», oui, car cet organisme s'est déployé sur plusieurs volets qui m'ont tous touché, un jour ou l'autre. De compositeur « sénior » commandé ou joué par l'ensemble, aux côtés des Daoust, Evangelista, Gougeon, Rea, Tremblay et autres Vivier - pour ne parler que des Québécois -, d'animateur de certaines activités de médiation pour l'Ensemble, je suis aussi devenu - lorsqu'entré au Conservatoire en 1997 pour y donner jusqu'en 2015 des cours de composition et d'analyse - le professeur de certains de ces nombreux «jeunes» compositeurs que l'ECM+ a pris sous son aile, de ceux-là qui, étudiants, avaient déjà bénéficié de leur rencontre avec Véronique tion de musique contemporaine (devenus plus tard MusiquAvenir), pour ensuite, éventuellement, être choisis comme participants aux ateliers et concerts de l'une des éditions du volet Génération, ou comme les sujets de plus amples et ambitieuses commandes professionnelles, de ces commandes qui ont souvent formé un socle solide pour des carrières en bourgeon. Il y a derrière tout cela, derrière cette espèce de « filière naturelle », une histoire de fidélité, de confiance, d'amitié, entre Véronique et ces jeunes, comme avec moi.

Véronique et moi partageons donc de fortes attaches à notre alma mater, le Conservatoire, dont elle conservera notamment, comme moi, le souvenir des classes d'analyse de Gilles Tremblay où rigueur et poésie ne s'excluaient pas, et une grande admiration pour ce compositeur et pédagogue (dont elle a superbement interprété les œuvres). C'est là qu'en l'esprit de Véronique fut allumée par Clermont Pépin, alors directeur, l'étincelle du projet ECM, né en 1987; là où, chargée depuis 1995 de la classe d'interprétation de musique contemporaine, elle s'acoquinera avec ses collègues du secteur création - dont moi - pour l'organisation et la réalisation d'événements pédagogiques et musicaux marquants (autour de Pousseur, de l'électroacoustique, de Nono, etc.), auxquels l'ECM se greffait souvent tout naturellement, et parfois avec des ramifications internationales (avec Bordeaux, avec le Festival Cervantino, etc.); là aussi qu'elle décèlera quelques interprètes de talent qui bénéficieront du volet Relève, voire deviendront membres à part entière de l'Ensemble professionnel. 
Et il y a jusqu'au volet Jeunesse de l'ECM+ qui m’ait rejoint, avec ce conte musical Gros Paul que j'ai commis, coparrainé par le Moulin à Musique.

Dès notre premier projet commun (mon concerto pour piano Adonwe, 1994), j'ai pu mesurer l'exigence que Véronique nous fixe tous, musiciens comme compositeurs. Décisions de coupures, de réécritures (jusqu'à l'obtention d'une partition la plus conviviale possible): le travail n'est jamais fini! Et puis, cette conscience des nuances, des tempi, de la respiration, et cette volonté de faire saisir aux interprètes leurs significations (de façon parfois très imagée!). Lentement, patiemment, efficacement, s'élabore le succès: ce moment de musique qui rejoindra l'auditeur. Même chose pour Le cheminement de la baleine (1998); puis pour le projet québéco-mexicain Pont de papillons pour lequel a été écrit Relais Papillons (2009); et enfin, jusqu'à la commande du troisième volet de Microphone Songs, créé en 2010 dans le cadre d'un échange Montréal-Bordeaux. Mes projets avec l'ECM (+ ou non) ont toujours été pour moi l'occasion de la mise au monde d'œuvres que je considère comme majeures dans ma production, l'exigence de l'interprète et de la directrice artistique impulsant celle du compositeur.

Mais c'est aussi en tant que membre du Conseil d'administration de l'ECM+ (entre 2007 et 2013) que j'ai mesuré l'autre volet de l'exigence de Véronique, celui de la femme «d'affaires». Avec l'appui indéfectible de sa conjointe Natalie Watanabe et des personnes de qualité réunies autour de la table de ce Conseil, elle réalise des prouesses et établit, pour assurer l'avenir de son Ensemble, des standards sur les plans de la santé financière et des initiatives promotionnelles.

Fidèle tu es, chère Véronique, à ton exigence et à tout un milieu. Fidèle je serai, au concert comme ailleurs, comme beaucoup d'autres de ce milieu qui t'apprécient et te suivent avec l'ECM +. 